\title{
Pharmaceutical risk communication: sources of uncertainty and legal tools of uncertainty management
}

\section{DRAFT}

\author{
Barbara Osimani, PhD
}

Original paper in: Osimani, B, (2010) Health Risk and Society, October, Volume 12 Issue 5: 453-469.

\begin{abstract}
Risk communication has been generally categorized as a warning act, which is performed in order to prevent or minimize risk. On the other side, risk analysis has also underscored the role played by information in reducing uncertainty about risk. In both approaches the safety aspects related to the protection of the right to health are on focus. However, it seems that there are cases where a risk cannot possibly be avoided or uncertainty reduced, this is for instance valid for the declaration of side effects associated with pharmaceutical products or when a decision about drug approval or retirement must be delivered on the available evidence. In these cases, risk communication seems to accomplish other tasks than preventing risk or reducing uncertainty.

The present paper analyzes the legal instruments which have been developed in order to control and manage the risks related to drugs - such as the notion of "development risk" or "residual risk" - and relates them to different kinds of uncertainty. These are conceptualized as epistemic, ecological, metric, ethical, and stochastic, depending on their nature. By referring to this taxonomy, different functions of pharmaceutical risk communication are identified and connected with the legal tools of uncertainty management.

The purpose is to distinguish the different functions of risk communication and make explicit their different legal nature and implications.
\end{abstract}

Keywords: Risk communication, risk management, risk epistemology, precautionary principle, residual risk, development risk, well founded suspicion. 


\section{Introduction}

Pharmaceuticals can be considered as "credence products", i.e. products which are purchased with little or no direct appraisal of their quality and are therefore surrounded by considerable uncertainty. This circumstance and the several pharmaceutical scandals which have accompanied the history of pharmacology have increasingly contributed to the development of a strict regulation with the aim to protect the consumer through quality, efficacy and safety control. This has enriched the list of care duties for pharmaceutical companies, generally also accompanied by deontology codes of self-regulation from the side of the industry (Scheu, 2003: 5960 ), enlarged the intervention powers of the responsible authority, and amplified the responsibility spheres of all concerned parties (for a historical contextualization of this evolution see Scheu, 2003; a fundamental reference to the evolution of risk regulation in Germany is Di Fabio, 1994).

These measures though, do not constitute an absolute guarantee of health protection: however carefully designed and manufactured, pharmaceutical products can produce unpredictable reactions in the different organ systems. For this reason, drugs are considered "unavoidably unsafe" products.

Awareness of this state of affairs dramatizes the role of communication, given the importance of updated, relevant and timely information for risk prevention and minimization. Indeed, the legislator's activity has focused on a series of instruments in order to provide a detailed structure of information disclosure duties both for the industry and for the responsible authority.

However, the complexity and contradictoriness of data documenting drug efficacy and risks, the conflict of interest affecting the principal investigators of chemical entities and information deliverers (pharmaceutical sponsors), as well as time constraints, can be considered at the origin of much discontent about how pharmaceutical decisions are taken both by responsible authorities and the pharmaceutical industry (Reiss \& Kitcher, 2008; Abraham \& Davis, 2005; Abraham $\&$ Reed, 2001, Demortain, 2008).

This has become manifest at a macroscopic level in many recent and past scandals related to drugs eventually removed from the market, such as the unhappily famous case of the tranquilizer Contergan $($ ) (Thalidomide) in Germany, which caused severe birth defects (mainly caused by drug inducted phocomelia) to more than 6000 children and fatally injured 2500 people (1957-1961). More recently Lipobay@, Vioxx $\odot$, and Bextra $\odot$ are all associated to opaque communication strategies both by the industry and by the responsible authority. Santoro (2005) offers a lucid analysis of the dramatic image decline suffered by the pharmaceutical industry in recent years. According to the Harris Poll, the public perception that the pharmaceutical industry was adequately serving its customers sank from a $79 \%$ adults believing so in 1997 to 44\% in 2004 (Santoro, 2005: 3). 
It seems though that neither reputation concerns nor fears that patients will sue are sufficient incentives to virtuous communication and transparency as long as information disclosure is linked to huge variation in stock exchange fluctuations and investment returns. One of the reasons which are at the basis of communication opacity is the lack of clarity about the different tasks which risk communication accomplishes in the pharmaceutical field. The purpose if this paper is to differentiate between these tasks and link them to the legal tools developed in the pharmaceutical setting in order to manage the different sorts of uncertainty affecting drugs and allocate the related risk responsibility. The legal setting considered here is the German one. However, most of the legal constructs developed across western countries in order to manage pharmaceutical risks are common, therefore the argumentation articulated in the paper is not limited to the German setting.

\section{Sources of uncertainty affecting the pharmaceutical product}

Three main aspects can be considered responsible for different types of uncertainty surrounding the pharmaceutical product:

1. Product opacity. This relates to the inscrutability of drugs: neither their galenic form, nor their colour or taste can give any hints as to the effects which they bring about in the human body. Insights about the drug effects are only indirectly acquired through theoretical knowledge and empirical investigations of various evidential value (phase I-IV studies). Product opacity generates "epistemic uncertainty": the portion of ignorance regarding its effects and side-effects in the organ system (the "yet-unknown risk").

2. Product ambiguity. This relates to the fact that the drug both promotes and endangers health. Therefore, because both the therapy as well as the illness are connected to a certain amount of risk, uncertainty is generated by the alternative between drug or illness risk ("ecologic uncertainty" or indecision).

3. Dependence of the effect on the user's profile. Both drug efficacy and risk are strongly dependent on the individual susceptibility to the drug: "Risk is not evenly distributed ... Some patients are at very high risk and others at essentially zero risk, the challenge is to define that individual risk" (Spielberg, 1993: 31, 32; see also Waller, Evans, 2003: 22). The uncertainty deriving from this state of affairs can be termed "stochastic uncertainty": i.e. the uncertainty generated by the variance of the drug effects on the population of users. Stochastic uncertainty relates to potential risks which have been identified, but whose probability of occurrence for the individual user cannot be estimated confidently, because each drug user has a different sensitivity to different chemical products (both in terms of positive therapeutic effects as well as in the sense of adverse drug reactions: ADRs).

In the following sections the interconnection between these product characteristics and the different uncertainty types originating from them are connected to the legal tools devised in order to cope with any specific sort of uncertainty; finally, the last part of the paper is devoted to the link between uncertainty types and risk communication functions. 
The following table should guide the reader in following the paper presentation:

\section{Sources of uncertainty and risk communication functions in the pharmaceutical field}

\begin{tabular}{|c|c|c|c|c|c|c|}
\hline \multirow[t]{2}{*}{$\begin{array}{l}\text { Source of } \\
\text { uncertainty }\end{array}$} & \multirow[t]{2}{*}{$\begin{array}{l}\text { Type of } \\
\text { uncertainty }\end{array}$} & \multicolumn{2}{|c|}{$\begin{array}{l}\text { Legal tools adopted to manage } \\
\text { uncertainty }\end{array}$} & \multirow{2}{*}{$\begin{array}{l}\text { Risk } \\
\text { communication } \\
\text { functions }\end{array}$} & \multirow[t]{2}{*}{$\begin{array}{l}\text { Protected } \\
\text { right }\end{array}$} & \multirow[t]{2}{*}{$\begin{array}{l}\text { Illocutionary } \\
\text { point }\end{array}$} \\
\hline & & Principles & Critical issues & & & \\
\hline \multirow[t]{2}{*}{ Opacity } & \multirow[t]{2}{*}{ Epistemic } & \multirow[t]{2}{*}{$\begin{array}{l}\text { Development } \\
\text { risk and well } \\
\text { founded } \\
\text { suspicion }\end{array}$} & \multirow{2}{*}{$\begin{array}{l}\text { Single and } \\
\text { cumulative } \\
\text { causal } \\
\text { assessment; } \\
\text { Well founded } \\
\text { suspicion } \\
\text { threshold }\end{array}$} & $\begin{array}{l}\text { Reduction of } \\
\text { epistemic } \\
\text { uncertainty: } \\
\text { Update drug risk } \\
\text { profile }\end{array}$ & \multirow{4}{*}{ HEALTH } & Inform \\
\hline & & & & $\begin{array}{l}\text { Avoidance/ } \\
\text { minimization of } \\
\text { avoidable risk }\end{array}$ & & $\begin{array}{l}\text { Instruct } \\
\text { (warning) }\end{array}$ \\
\hline & & & & & & \\
\hline \multirow[t]{3}{*}{ Ambiguity } & \multirow[t]{3}{*}{ Ecological } & \multirow{3}{*}{$\begin{array}{l}\text { Risk-benefit } \\
\text { assessment } \\
\text { Distinction } \\
\text { between } \\
\text { Residual risk } \\
\text { vs. } \\
\text { unacceptable } \\
\text { risk }\end{array}$} & \multirow{3}{*}{$\begin{array}{l}\text { Metrical } \\
\text { uncertainty } \\
\text { Ethical } \\
\text { uncertainty }\end{array}$} & \multirow{2}{*}{$\begin{array}{l}\text { Reduction of } \\
\text { ecological } \\
\text { uncertainty } \rightarrow \\
\text { Risk-benefit } \\
\text { optimization }\end{array}$} & & Inform \\
\hline & & & & & \multirow{2}{*}{$\begin{array}{c}\text { SELF- } \\
\text { DETERMIN } \\
\text { ATION }\end{array}$} & $\begin{array}{l}\text { Strategic } \\
\text { communication } \\
\text { (agreement) }\end{array}$ \\
\hline & & & & Liability transfer & & Disclaim \\
\hline \multirow{4}{*}{$\begin{array}{l}\text { Dependence } \\
\text { on user's } \\
\text { personal } \\
\text { sensitivity }\end{array}$} & \multirow[t]{4}{*}{ Stochastic } & \multirow{4}{*}{$\begin{array}{l}\text { Doctor is } \\
\text { responsible for } \\
\text { optimal } \\
\text { individual } \\
\text { therapy }\end{array}$} & \multirow{4}{*}{$\begin{array}{l}\text { Complexity of } \\
\text { individual risk- } \\
\text { benefit } \\
\text { assessment } \\
\rightarrow \text { Individual } \\
\text { residual risk } \\
\text { threshold }\end{array}$} & $\begin{array}{l}\text { Reduction of } \\
\text { stochastic } \\
\text { uncertainty }\end{array}$ & \multirow[t]{2}{*}{ HEALTH } & Inform \\
\hline & & & & $\begin{array}{l}\text { Avoidance/ } \\
\text { minimization of } \\
\text { avoidable risk }\end{array}$ & & $\begin{array}{l}\text { Instruct } \\
\text { (warning) }\end{array}$ \\
\hline & & & & $\begin{array}{l}\text { Choice } \\
\text { optimization; }\end{array}$ & \multirow{2}{*}{$\begin{array}{l}\text { SELF- } \\
\text { DETERMIN } \\
\text { ATION }\end{array}$} & $\begin{array}{l}\text { Shared decision } \\
\text { making } \\
\text { (agreement) }\end{array}$ \\
\hline & & & & Liability transfer & & Disclaim \\
\hline
\end{tabular}

Table 1: The different functions and illocutionary points of risk communication in relation to the types of uncertainty affecting the pharmaceutical product.

\section{Legal instruments of uncertainty management}

The different sources of uncertainty addressed above are responsible for much of the regulatory development related to pharmaceuticals: product opacity and the related epistemic uncertainty have been addressed by introducing the notion of development risk; similarly, product ambiguity and the related ecological uncertainty are managed through the risk-benefit assessment and the notion of residual risk; finally, the doctor 
is ascribed responsibility for taking into account the variance of effects on users (stochastic uncertainty).

\section{Epistemic uncertainty: Development risk}

Because drug reactions are idiosyncratic and depend on several epidemiological and genetic factors, knowledge about the effects of any drug grows with the number of its users. This means that even many years after approval, any pharmaceutical is still an "experimental product", the information about which is neither exhaustive nor conclusive.

The general recognition of the limited and fragmentary knowledge related to chemical and pharmaceutical technologies has raised the awareness that criteria for the management of the "unknown" are needed (See the Enquete-KommissionsBericht "Schutz des Menschen und der Umwelt": BT-DrS. 12/8260, cited in Scheu, 2003: 72). For most of the chemical products on the market, fundamental data about chemical behavior and environmental consequences of their use are simply not available (Scheu, 2003: 80).

A fundamental concept in this framework is the notion of "development risk" (design risk). This is the yet-unknown risk which goes undetected in the phase I-III trials and remains "hidden" while the drug, once approved, circulates in the market.

The legislator has predisposed a risk surveillance and management system, with the aim to monitor the drug approved to the market and observe its behaviour in order to prevent/minimize damage by timely detecting the development risk. The approval status is therefore unsteady and provisional. New data about the drug coming from the market may change the drug risk profile and require corresponding measures.

\section{The detection of development risk and the principle of well founded suspicion}

Given that the discovery of development risk is a matter of gradual accumulation of evidence and theoretical acquisition, waiting for the establishment of a causal connection before intervening would most times lead to late intervention and avoidable damage.

This state of affairs is at the origin of the recognition that the establishment of a causal nexus between drug and adverse effect cannot constitute a condition for safety interventions: "softer" epistemological-legal concepts such as probabilistic rather than categorical ones have been introduced in the legal system in order to better serve the protection of safety. ${ }^{3}$ This is the case of the concept of "well-founded suspicion" which covers the cases where a causal nexus cannot be proven but it is considered a plausible hypothesis.

\footnotetext{
${ }^{2}$ Drugs are products under constant testing (,Arzneimittel sind Produkte in Dauererprobung“) declared the Health Minister Dr. Focke in the ministerial statement for the provision of the German Medicines Act | (Arzneimittelgesetz 1976): Scheu, 2003: 701.
} 
The principle of well-founded suspicion can be considered as the "declination" of the precautionary principle in pharmaceutical regulation. According to the precautionary principle the authority and the industry are supposed to intervene with preventive measures even where there is no definitive evidence of the causal nexus between damage and source. Instead, they are supposed to act as soon as the probability of a causal connection is sufficiently high with respect to the potential harm. The higher the expected damage, the lower can be the probability of causal connection in order to require for intervention. (Di Fabio, 1994; Dettling, 2005: 165). A major problem with the principle of well founded suspicion however, is that neither a practical nor a formal rule have been defined in order to provide threshold measures and accountability criteria.

- Indicators of suspicion as derived from the interpretation of the relevant norms are rather vague and prone to biased interpretation: the alarm could be triggered by concrete cases of damage but also by new theoretical knowledge (Di Fabio, 1993: 126-127; Räpple, 1991: 90-91), or by a doctor's assessment of an association between an adverse drug reaction (ADR) and a drug (Di Fabio, 1993:125). Moreover the detection of development risk is severely limited by contextual obstacles such as:The objective difficulties affecting the diagnosis of side effects, and therefore their tendency to be underdetected (ADR identification); ${ }^{4}$

- Consequent lack of consistency in the way ADR events are identified and reported: statistical unreliability and invalidity due to inconsistent reporting and systematic underreporting (bias). ${ }^{5}$

ADR identification is particularly difficult because of the alternative explanatory causes possibly associated with bodily symptoms. This is especially valid in multimorbidity cases and in subjects who receive different treatments at the same time. In the case of reactions depending on the individual immune system (such as anaphylactic shocks, influenza-like syndromes and damage to the immune system (Schönhöfer, 1993: 96-98), the causal assessment is also complicated by the absence of any dose/time relationship between drug intake and ADR.

In the attempt to decrease heterogeneity and ambiguity of the data, several methods for assessing adverse medical events associated with drugs were introduced since the early 1980s. One of the most widespread is the Naranjo algorithm, but also the Karch and Lasagna operational method of assessing ADR is used by several companies; Edwards and Lindquist have created a list of quality criteria for causal assessment; Bégeaud et al. have created a method which differentiates among different drugs (see Meyboom et al., 1997 and Buckingham Stevens, 1997 for references).

However, innumerable cases of unjustifiably late product withdrawals (see for instance the Croniassal case in Germany, but also the Vioxx case or the Contergan

\footnotetext{
4

${ }^{5}$ The problem of underreporting is mentioned by several authors: Talbot, Nilsson, 1998: 428; HartmannBesche, 1998: 124; Di Fabio, 1993: 116; Räpple, 1991: 109; Schönhöfer et al. 1998: 111. Meyboom et al. 1997: 383. Consistency is flawed and biased towards underreporting also because of contingent factors: fear of possibly incurring in legal responsibility, and time constraints in the ambulatory workflow.
} 
case - for further examples see: Abraham \& Reed 2001; Abraham \& Davis 2005, Hart 1998) testify that more detailed yardsticks should be provided to the responsible authority and the industry as to increase data and decisionmaking consistency, as well as establish stronger accountability constraints. It is advocated that in such complex fields as pharmacology, decisions are taken on the basis of all available evidence and lack of thereof. ${ }^{6}$

\section{Ecological uncertainty: the distinction between acceptable vs. residual risk}

Given the ambiguous character of pharmaceuticals and the consequent impossibility of absolute safety, the evaluation of drugs cannot result in a distinction between riskless and harmful products, but rather between an acceptable ("zumutbar") and an unacceptable ("unzumutbar") risk (Räpple, 1991: 50-57). ${ }^{7}$ A risk tolerance threshold is established below which the drug is considered "unsafe".

This threshold is relative to the benefit expected from the drug through a risk-benefit evaluation: this decides how much risk is to be accepted in the face of how much benefit. The risk-benefit assessment is made on the basis of known risks and benefits and focuses on whether the known risk associated with the drug can be accepted in the face of its expected benefits. Therefore, the proportion of ignorance surrounding the drug (epistemic uncertainty) is only indirectly relevant here. The uncertainty affecting the risk-benefit assessment can be rather dubbed as "ecological" in the sense that pros and cons are weighed against each other in order to gauge the best action. The main implication of this procedure is that, if the drug is approved, then the related risk is considered part of the bargain: this is called "acceptable", "tolerable", "unavoidable" or "residual".

The term "unavoidable" refers to the consideration that absolute safety is unattainable and that some risks must be taken into account: a risk is unavoidable to the extent that it cannot be reduced or prevented unless one renounces altogether the technology which generates it. When the same benefit can be expected from an alternative technology which is associated with less risk, then the risk is considered avoidable, because it can be made without by resorting to the alternative technology. ${ }^{8}$

Unavoidable or tolerable risk is more often termed "residual risk": this because it is considered the risk which is insignificant enough in exchange of the expected benefit (Räpple, 1991: 110. Scheu, 2003: 713). However, being accepted does not mean being taken for granted: relevant residual risk is supposed to be disclosed to the

\footnotetext{
${ }^{6}$ A statistical methodology which can help with the integration of data coming from heterogeneous sources is the Bayesian paradigm: see the proposal advanced by Waller \& Evans, 2002, and author \& Russo, forthcoming).

${ }^{7}$ See also Räpple, 1991: 50-57.

${ }^{8}$ The distinction avoidable-unavoidable is used in the legal literature also in a different sense. This is when a risk can be avoided through intervention or precaution. This is related to measures which can be taken in order to minimize or prevent unexpected risks (development risk) or known residual risks. Among these measures, communication plays a fundamental role, which however differs from the function it has in the declaration of residual risk. This distinction will be treated in the last part of the paper.
} 
concerned parties: this is where risk communication is called to warrant for the right to know and to self-determination. ${ }^{9}$

\section{Risk-benefit assessment}

The condition for market approval is a positive risk-benefit assessment, in absolute terms (when no other drugs in the market compete with the candidate), as well as relative to the pharmaceutical environment (i.e. in relation to the treatments already present in the market for the same indication: Hart, 2005; author's 2007: chapter 2). This evaluation is based on a comparative weighting of therapeutic importance and efficacy on one side, and of risk severity and frequency on the other. The definition of risk traditionally adopted by safety regulations has been inherited from natural sciences and engineering and consists in the product of the two dimensions of damage severity and probability, where the damage is any injury caused to goods protected by the law (Räpple, 1991: 49).

In decision-theoretic terms, drug approval can be formalized as follows: EU (D) > $\mathrm{EU}(\neg \mathrm{D})$ :

The expected utility (EU) of drug approval (D) should be higher than that of drug refusal $(\neg \mathrm{D})$, where both utilities are computed out of the formulae:

$\mathrm{EU}(\mathrm{D})=\sum_{\mathrm{i}}\left[\operatorname{Prob}\left(\mathrm{i}_{\mathrm{D}}\right) \cdot \mathrm{U}\left(\mathrm{i}_{\mathrm{D}}\right)\right]$

$\mathrm{EU}(\neg \mathrm{D})=\sum_{\mathrm{j}}\left[\operatorname{Prob}\left(\mathrm{j}_{\neg \mathrm{D}}\right) \cdot\left(\mathrm{Uj}_{\neg \mathrm{D}}\right)\right]$.

The expected utility of drug approval is the sum of the "utility x probability" products for all relevant attributes $\left\{i_{1}, \ldots i_{n}\right\}$ associated with the drug (benefits, ADRs). Attribute utilities have a positive sign for the drug benefits and a negative sign for the adverse drug reactions.

The expected utility of drug rejection is the sum of the "utility x probability" products for all relevant attributes $\left\{\mathrm{j}_{1} \ldots \mathrm{j}_{\mathrm{n}}\right\}$ associated with this option: i.e. the negative consequences of not treating the illness with the drug on one side, and the avoidance of drug side effects on the other.

For any drug to be approved, the expected utility associated with it must be superior to that of not approving it.

All this is however "easier said than done": drug approval is a multistage process, where a huge amount of information coming from heterogeneous sources contribute to the final decision. The ecological uncertainty affecting the risk-benefit assessment increases to the extent that the difference among the inequality factors approaches zero; i.e., when $\mathrm{EU}(\mathrm{D}) \approx \mathrm{EU}(\neg \mathrm{D})$. This might be due to compensatory attributes present in both the risk and the benefit side. Whereas in the risk management process described above, risk communication has mainly a safety function (health protection), in the risk-benefit assessment it also warrants for the inclusion of

\footnotetext{
${ }^{9}$ Residual risk may have a different threshold in drug approval and drug prescription. In the decision concerning drug marketing, the benchmark for comparing benefit and risk refers to the relevant population. Instead in the single prescription, the doctor should compare the individual risk faced by the single consumer to the expected therapeutic outcome on the basis of his specific health profile and disease condition. Therefore residual risk splits into product and therapeutic residual risk.
} 
specific agendas as expressed by the different interest groups. Considering the conflicts of interests which characterizes the approval decision, communication among different stakeholders leads in this setting to strategic maneuvering and persuasive communication.

The ecological uncertainty affecting the risk-benefit assessment is amplified by two further sources of uncertainty: metrical and ethical.

Metrical uncertainty relates to the difficulties encountered in trying to measure the relevant decision parameters. Prolongation of life expectancy is one of the most common parameters considered in health technology assessment. More precisely, technologies are evaluated in terms of quality adjusted life expectancy. In the case of pharmaceutical products this factor is integrated with other relevant parameters such as therapeutic importance, efficacy degree, symptoms relief, side effects severity and frequency (Hart, 2005: 209; Besch, 2000: 55-56; Räpple, 1991: 107-108; Wolz, 1988: 79). Major difficulties in the measurement of these parameters can be summarized under the following points: ${ }^{10}$

The quantification of some factors is especially difficult to establish;

a. The preference values associated to these factors may differ from individual to individual and from group to group of stakeholders with consequent variance of risk acceptance (see below);

b. Both the risk magnitude and probability are different for each user depending on his personal sensitivity to the drug components (stochastic uncertainty);

The scientific knowledge at the basis of the measurement is heterogeneous and often controversial;

As a consequence, no standardized operationalization of these parameters has taken place (Besch, 2000: 55; Räpple, 1991: 113-11).

Ethical uncertainty surrounding drug approval decisions is generated among other by the fact that both rejection and approval bring about potential health dangers. In fact, if conditions for marketing approval are too strict, then specific patient groups suffer from not being able to be cured; if, on the other hand, they are too liberal, than the population of users is exposed to a greater risk in terms of side effects magnitude and/or probability.

Moreover, this uncertainty is complicated by the fact that the approval decision affects different members of the population in different ways. This generates a question of social justice, fundamentally amenable to three factors:

1. heterogeneous sensitivity in the population;

2. heterogeneous preference values concerning health issues;

3. and heterogeneous risk acceptance as a consequence of both.

These are very important from a policy perspective, because they can explain much of the potential variance in pharmaceutical risk decisions across countries and historical phases.

\section{Stochastic uncertainty: Dependence on consumer's sensitivity}

\footnotetext{
${ }^{10}$ See Hughes et al. 2007 and Temple, 2007 for an example of comparison between benefits and risks of terfenadine, chlorpherinamine, and loratidine.
} 
Age $^{11}$, sex, genetic make-up, physiological changes, exogenous factors (drug-drug or food-drug interference) and disease-drug interaction influence the patient's susceptibility to adverse drug reactions. Also ethnicity seems to be a carrier of factors (environment, genetics, lifestyle) determining higher or lower susceptibility to drug efficacy ${ }^{12}$ and side effects as well. ${ }^{13}$

The individual degree of susceptibility to a specific drug depends on the combination of the diverse parameters: conditional on their personal health profile, two individuals can show dramatic different reactions to the same molecular entity. Therefore, a drug which has a general positive risk/benefit assessment can show a negative risk/benefit profile for a specific user. Given that the doctor who prescribes the drug is in the best position to acquire relevant clinical information about the patient and learn about his therapeutic preferences, the prescription of such an approved drug is considered medical error. Whereas pharmaceutical firms are liable for product safety; the doctor is liable for therapy safety (Hart, 2003, 603. Francke, Hart, 1999: 60). This means that he is supposed to minimize the therapeutic risks by choosing the product which best suits the patient's risk profile for the required indication. The legislator considers the doctor (under both contract and tort law) responsible for:

- assessing the patient's personal susceptibility on the basis of his genetic parameters, health history, clinical profile, lifestyle and actual health conditions;

- prescribing the patient a therapy with an individually favorable risk-benefit assessment;

- communicating to him both the risks and benefits associated with the therapy. ${ }^{14}$

The requirement of individual risk-benefit optimization through the doctor implies a two-way communication exchange. Not only should the doctor provide information and instructions to the patient, but he should also elicit from him clinically relevant information (in order to reduce the stochastic uncertainty and therefore best warrant

\footnotetext{
${ }^{11}$ The risk of contact allergy to neomycin sulfate seems for instance to vary with age and increase with the number of additional positive reactions to other standard series allergens. Menezes de Pádua et al. (2005).

12 "Ethnic group may act as a marker for underlying genetic or environmental differences in this susceptibility" McDowell et al. (2006): 4. McDowell et al. (2006): 1. Relevant cases with regard to this point are the recent approval of isosorbide dinitrate plus hydralazine (BiDil) limited to the use in black patients: McDowell et al. (2006): 1.

${ }^{13}$ A meta-analysis on the literature devoted to the investigation of the relationship between ethnicity and ADRs to cardiovascular drugs has for instance delivered the result that the relative risk of angio-oedema from ACE (angiotensin converting enzyme) inhibitors in black patients is 3.0 compared to non-black patients (C.I. 95\%: 2.5 to 3.7); the relative risk of cough in concomitance with ACE inhibitors is 2.7 when compared between East-Asians and white patients (C.I. 95\%: 1.6 to 4.5); and the relative risk of intracranial haemorrhage with thrombolytic therapy is 1.5 (C.I. 95\%: 1.2 to 1.9). McDowell et al. (2006): 23. See also Henry et al., 1996 for gastrointestinal reactions to NSADs.

${ }^{14}$ In the U.S. the theory of the learned intermediary relates precisely to the inadequacy of product information as a basis for individual prognosis: the doctor intermediates between the pharmaceutical firm and the drug consumer by selecting the appropriate product on the basis of an individual risk-benefit assessment and is also supposed to be in the best position for selecting the appropriate information the consumer about his personal risk-benefit prognosis. See Ferguson, 1992, for discussion. See also Calman, 1996 and more recently, Author's, 2007, chapter 6, for a general discussion on the problems related to communicating probability of risks in these settings.
} 
for health protection), and his preferences (in order to optimize the choice through shared decision-making and honor his right to self-determination).

\section{Pharmaceutical risk communication}

Risk communication has been generally dubbed under the label of "warning". In classical speech act theory, the act of warning is defined as a subtype of suggestion (which is a "directive" or instruction): to recommend not doing something. This is an exact categorization for risk communication regarding precautionary behavior, i.e. instruction about correct measures for preventing/minimizing avoidable risk (see below); however it cannot capture, that part of health risk communication addressing the eventuality of damage notwithstanding adherence to precautions, i.e. communication of "residual risk".

On the other hand, risk analysis and decision theory scholars analyses communication in terms of uncertainty reduction. But the preceding analysis has showed that some kinds of uncertainty (e.g. "ecological uncertainty") are not necessarily reduced through the acquisition of further information. ${ }^{15}$ Therefore, in this case too, communication must accomplish other (or additional) purposes.

In the following, a taxonomy of risk communication functions with a special focus on their legal nature is illustrated by drawing on the categories developed within speech act theory.

\section{Rights, duties and responsibilities}

Pharmaceutical regulation responds to the protection of two fundamental goods:

- Right to health and life protection;

- Right to self-determination.

Both goods are constitutionally protected. There has been an ongoing debate in the bioethical and legal medical literature as to which one between the two should be given priority in case of conflict (for an overview see: Faden, Beauchamp, 1986). In any case, these rights bring into play specific duties and responsibilities for all the stakeholders involved. These result in a complex configuration of legal constraints which not only sets the protocol for drug approval, prescription and risk management, but also characterizes the nature of the communication acts involved.

\section{Communication acts}

Communication acts among agents can be examined in terms of the institutional effects which they bring about. These are the changes which entities undergo with regard to their status, authority, duties, rights, and responsibilities in a given fragment

\footnotetext{
${ }^{15}$ This is the topic of so called "sensitivity analysis", the branch of decision theory devoted to the estimation of information value conditional on its capacity to change the decision.
} 
of social reality (Colombetti et al. 2003: 80) This approach is especially appropriate when analyzing the functioning of communication acts in a legal environment.

Following the distinction between performative and assertive enunciates (Austin, 1955) and the taxonomy of illocutionary acts proposed by Searle and Vanderveken (1989), Colombetti et al. (2003) postulate that any message in an institutional context is a performative, in that it operates an institutional effect (for instance "I declare the session closed"): The institutional effects are determined by the institution norms, authorities and responsibilities of the agents involved.

Five main categories of speech acts along five illocutionary points are distinguished:

i. $\quad$ assertive (e.g. statements);

ii. commissive (e.g. promises);

iii. directive (e.g. orders);

iv. declarative (e.g. declarations);

v. expressive (e.g. congratulations). ${ }^{16}$

Following this taxonomy, the different functions of risk communication can be examined in terms of their illocutionary point and related components.

\section{Communication of development risk: inform}

In the paragraph devoted to the analysis of development risk and well-founded suspicion, it has clearly emerged that the timely delivery of risk information is a cornerstone of the precautionary principle.

Doctors as well as the pharmaceutical firm are responsible for disclosing any suspicious fact which could modify the drug risk profile. In this context information has principally the function to reduce epistemic uncertainty, in that it helps amplify the knowledge about the pharmaceutical product and update its risk profile.

However, there is an institutional component too: within the risk management process, anyone who learns about relevant facts associated to the drug (through pharmacosurveillance, observational studies or theoretical analysis) will be held liable for not disclosing that information.

In fact in an institutional context, "being informed" is a sufficient condition for being held responsible about the implications of the information according to one's own role, authority and responsibilities.

In this specific context, not only has the liability threshold been lowered from certain to probable causal assessment through the introduction of the principle of well founded suspicion, but, more generally, the risk management process mandates that any relevant fact about the drug be disclosed and systematically collected in order to detect the yet-unknown risk.

\footnotetext{
${ }^{16}$ Different speech acts with the same illocutionary point can be distinguished on their turn through "operations" on the seven components constituting the illocutionary force. For example reporting differs from asserting because of the different propositional condition that the event reported be either in the past or in the present, but not in the future (p. 187); requesting differs from ordering for the position of authority of the speaker (mode of achievement) (p. 201); promising differs from theratening for the presupposition (preparatory condition) that the state of affair described by the propositional content is good for the hearer, whereas in the threat this is bad (Searle and Vanderveken, 1989: 203).
} 


\section{Risk-benefit assessment: information and strategic communication}

If information related to the discovering of development risk should update the drug risk profile, information at the basis of the risk-benefit assessment should provide the basis for deciding whether its expected benefit exceeds the associated risk. In this sense too, the information provided by the pharmaceutical sponsor for drug approval/circulation in the market, accomplishes epistemic purposes.

However, in the measure that the approval decision is affected by ecological uncertainty, i.e. that $\mathrm{EU}(\mathrm{D}) \approx \mathrm{EU}(\neg \mathrm{D})$, so is the decision sensitive to any change of the weights assigned to the different parameters. Proportionally, strategic maneuvering across interest groups in order to assign more weight to one's own preferred parameters tends to increase and give space to persuasive communication in the decision process (towards an act of agreement among the parts), both among experts as well as towards the public. At worst, information concealment, falsified data and deceitful communication are possible options if stakes are high and deterrents weak enough.

\section{Communication of residual risk: risk disclaimer}

Being residual risk (e.g. side effects) unavoidably connected to drug intake, the only way to avert it would be to refuse drug approval or to renounce the therapy.

Residual risk information is therefore not aimed to avert damage through precautionary warning (which would correspond to health protection), but rather to honor the patient's right to self-determination, in that he can decide on its basis, whether to undergo the risk or not and give his consent to the therapy.

More significantly, through this information, consent is considered valid, and consequently the responsibility for the residual risk is transferred to the drug consumer: the risks not due to professional errors (negligent prescription or product faultiness) are shouldered by the patient. As a consequence, information about residual risk amounts to a disclaimer.

\section{Communication of avoidable risk: conditional risk disclaimer and warning}

Whenever communication provides instructions about appropriate measures for controlling/minimizing/preventing the risk, then this can be either categorized as an act of warning or as an act of advise, in that it is a suggestion not to do or to do something in order to avoid something bad. This is the case of communication about avoidable risk.

However, given the legal constraints, also this type of communication can have disclaiming functions: warning/advising can be considered in this setting a sort of "conditional" risk disclaimer. In fact in liability regulation, not following the instruction delivered in the package leaflet or by the doctor can result in being claimed for contributory liability in case a damage occurs. The following paragraph 
illustrates this point by referring to doctor-patient communication (similar considerations apply also to product instructions). ${ }^{17}$

\section{Doctor patient communication}

The distinction between preventive and purely disclaiming function of risk communication is especially exemplified by rules of damage compensation in doctor-patient communication, where compensation for material damage claimed on the basis of violation of information duties is fundamentally decided along three conditions:

1. Duty to inform: Was there a duty to inform on the basis of the medical knowledge available?

2. Breach of duty: Was the information delivered (in a sufficient and adequate way)?

3. Causality of breach for damage: Was the failure to provide due information relevant for damage occurrence?

Depending on the nature of information, causality for damage can be established in two different senses:

a. In the case of information about avoidable risk, a warning failure can be at the origin of the damage in the sense that the patient would have not been damaged if, adequately informed, he would have behaved consequently.

b. In the case of information about residual risk, the causality link depends on the materiality of the information to the decision: Was the missing risk information relevant to the decision? Or would the patient have decided in the same way, also if adequately informed about the damage for which he is suing the doctor?

The following scheme summarizes the liability framework which regulates doctor responsibility in case of health damage in Germany:

\footnotetext{
${ }^{17}$ Author's 2007 presents a distinction of the responsibility spheres (patient, doctor, pharmaceutical firm) concerning drug damage in relation to information duties.
} 


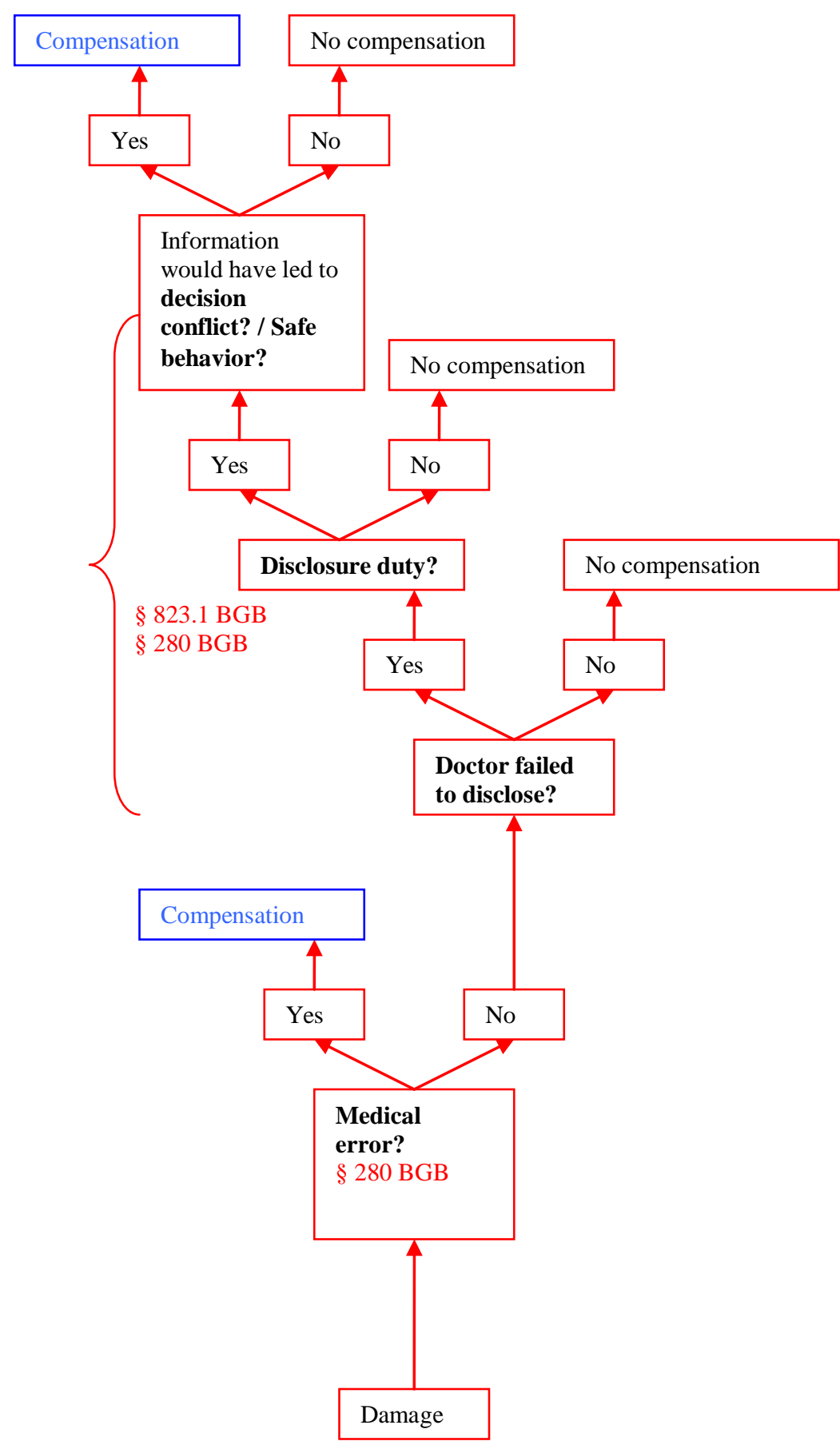

Figure 1: Algorithmic scheme for liability compensation in case of health damage in the German regulation $($ BGB $=$ Bundesgesetzbuch)

Compensation takes place if it can be established that, given the medical knowledge available at time of therapeutic consultation, there was a duty to inform about the risk of a damage, as the one under consideration in the litigation; that the doctor has failed to (adequately) inform about it; and that the patient would have behaved differently/ would have found himself in a decisional conflict, if informed about it. 
A legal consequence of this setting is that the patient shoulders the risks he has been made aware of prior to intervention/therapy: he shoulders the damage considered as a realization of residual risk, when previously informed about it; he shoulders also damage coming from avoidable risk when, notwithstanding the fact that he has been informed about appropriate actions to adopt for preventing it, he has not followed the instructions.

In both cases, information equates to a risk disclaimer. However, in the case of avoidable risk, damage can be avoided through adequate precautionary behavior, therefore the main point of informing about it is to possibly prevent it, or at least minimize it. Communication has mainly a warning function and it is a risk disclaimer only conditional on the fact that the receiver does not follow it.

Instead, in the case of residual risk disclosure, there is nothing that can be done or not, in order for damage to be avoided. Therefore, from a legal perspective, the point of informing about residual risk can only be to make the decision-maker aware about it. The legal effect is to transfer the residual risk from the doctor's responsibility to the patient's shoulders with no effect on its probability of occurrence.

Besides the disclaiming function accomplished by risk disclosure, doctor-patient communication is also aimed to achieve other purposes.

During the anamnesis (that is the dialogue through which the doctor acquires information about the patient's symptoms and health profile) the doctor collects relevant clinical information which help him diagnose the health status of the patient and reduce the stochastic uncertainty as to the therapeutic prognosis. Futhermore, beyond its diagnostic and prognostic purposes, the anamnesis also aim to identify the patient's preferences as to the therapeutic alternatives and information need. Therefore it is an essential tool in the promotion of the patient's right to selfdetermination through shared-decision making, with the ultimate goal of optimizing the therapeutic choice not only in relation to the expected probability of adverse reactions and efficacy, but also in relation to the patient's personal preferences.

\section{Summary and conclusion}

This study has outlined some interconnections between epistemological, juridical and communicative aspects related to the management of pharmaceutical risk. The legal tools developed within the pharmaceutical regulation (development risk, wellfounded suspicion, residual risk, risk-benefit assessment, the intermediary role of the prescribing doctor) have been traced back to the different sources of uncertainty affecting the pharmaceutical product (epistemic, ecological, ethical, metrical and stochastic). At the same time different functions of risk communication have been identified in relation to these legal instruments of risk management.

Finally the legal nature of the communicative acts which are at the basis of the identified risk communication functions have been presented and examined.

The main contribution of this research is that it distinguishes the different functions of risk communication and makes explicit their different legal nature. This taxonomy provides a comprehensive account of the goods at stake (health or selfdetermination), the type of risk involved (residual, development, etc.) and the related 
liability spheres in relation to different risk communication contexts. From a theoretical perspective, the distinction of different types of communicative actions in the risk context significantly contributes to the clarification of contradictions possibly emerging from the coalescing of inherently different communicative goals into one and the same category (e.g. "warning").

Message designers, policy makers, consumer associations as well as health and industry professionals can use this classification in order to develop a diversified approach to the design and ethical as well as juridical evaluation of risk communication messages.

\section{References}

Austin, J. (1954) How to do things with words

Abraham, J., T. Reed (2001) Trading risks for markets: The international harmonization of pharmaceutical regulation. Health, Risk \& Society, 3 (1): 113-128.

Abraham, J., C. Davis (2005) Risking public safety: Experts, the medical profession and "acceptable" drug injury. Health, Risk \& Society, 7 (4): 379-395.

Author (2007) Probabilistic information and decision making in the health context: The package leaflet as a basis for informed consent. PhD Dissertation, Lugano.

Author, F. Russo (forthcoming). Scientific evidence and the law: A Bayesian formalization of the precautionary principle in pharmaceutical regulation.

Besch, V. (2000) Produkthaftung für fehlerhafte Arzneimittel. Eine Untersuchung über die materiellund verfahrens-, insbesondere beweisrechtlichen Probleme des Arzneimittelhaftungsrechts. BadenBaden, Nomos.

Buckingham Stephens, M. D. (1997) From causality assessment to product labelling. Drug Information Journal, 31: 849-857.

Colombetti, M., N. Fornara, M. Verdicchio 2003, Speech Acts in artificial agent communication. In: Giacalone Ramat, A., Rigotti, E., Rocci Andrea (eds.) Linguistica e Nuove Professioni. Franco Angeli: Milano.

Demortain, D. (2008) From drug crises to regulatory change: The mediation of expertise. Health, Risk \& Society, 10 (1): 37-51.

Dettling, H.-U. (2005) Arzneimittelrecht als Sicherheitsrecht - Zugleich ein Beitrag zur Rechtfertigung von Freiheitsbeschränkungen. PharmR, 4: 162-173.

Di Fabio, U. (1993) Gefahrbegriff und Nachmarktkontrolle. In: Damm/Hart, 1993: 109-131.

Di Fabio, U. (1994) Risikoentscheidungen im Rechtsstaat : zum Wandel der Dogmatik im öffentlichen Recht, insbesondere am Beispiel der Arzneimittelüberwachung. Tübingen : Mohr.

Faden, Ruth. R, Beauchamp Tom L., (1986) A History and Theory of Informed Consent. New York: Oxford University Press. 
Ferguson, P.R. (1992) Liability for Pharmaceutical Products: A Critique of the 'Learned Intermediary Theory'. Oxford Journal of Legal Studies, 12 (1): 59-82.

Francke, R., D. Hart (1998) Charta der Patientenrechte. Nomos: Baden-Baden.

Fülgraff, G. (1978) Wie sicher sind Arzneimittel? Bundesgesundheitsblatt: 177 ff.

Goldstein D.B., A.C. Need, R. Singh, S.M. Sisodiya (2007) Potential causes of heterogeneity of treatment effects. American Journal of Medicine, 120: 21-25.

Hart, D.(1998) Zum Management von Arzneimittelrisiken durch Ärzte und Unternehmen Rechtsverfassung, Sozio-Psychologie, Empirie. In V. Preuss (ed.) (1998) Risikoanalysen. Über den Umgang mit Gesundheits- und Umweltgefahren. Vol II. Heidelberg: Roland Asanger: 165-203.

Hart, D. (2003) Arzneimittelinformation zwischen Sicherheits- und Arzthaftungsrecht. Fach- und Gebrauchsinformation, ärztliche Aufklärung und Pflichtverletzung. MedizinRecht, 11: 603-609.

Hart, D. (2005) Die Nutzen/Risiko-Abwägung im Arzneimittelrecht. Ein Element des Health Technology Assessment [1]. Bundesgesundheitsblatt-Gesundheitsforschung- Gesundheitsschutz, 48: 204-214.

Hartmann-Besche, W. (1998) Risikodiskurs und Pharmastandort Deutschland. In: Hart, D.; Kemnitz, W.; Schnieders C. (Hrsg.) Arzneimittelrisiken: Kommunikation und Rechtsverfassung. Nomos, Baden Baden, pp. 121-128.

Henry D, Lim LL, Garcia Rodriguez LA, Perez Gutthann S, Carson JL, Griffin M, Savage R, Logan R, Moride Y, Hawkey C, Hill S, Fries JT. (1996) Variability in risk of gastrointestinal complications with individual non-steroidal anti-inflammatory drugs: results of a collaborative meta-analysis. BMJ Jun 22; 312(7046):1563-6.

Hughes, D.A., A.M. Bayoumi, M. Pirmohamed (2007) Current Assessment of Risk-Benefit by Regulators: Is It Time To Introduce decision Analyses? Clinical Pharmacology \& Therapeutics, vol. 82 (2): 123-127.

Krudop-Scholz, K. (2005) Die ärztliche Aufklärungspflicht bei der Arzneibehandlung. Sicherungsund Selbstbestimmungsaufklärung auch bei Routinebehandlungen Peter Lang, Frankfurt am Main.

McDowell, S. E., Coleman, J. J., Ferner R. E. (2006) Systematic review and meta-analysis of ethnic differences in risks of adverse reactions to drugs used in cardiovascular medicine. British Medical Journal, BMJ doi: 10.1136/bmj.38803.528113.55 (published 5 May 2006).

Menezes de Pádua, C.A., A. Schmuch, H. Lessmann, J. Geier, A. Pfahlberg, W. Uter (2005) Contact allergy to neomycin sulfate: results of a multifactorial analysis. Pharmacoepidemiology and Drug Safety, 14: 725-733.

Meyboom R. H., Y. A. Hekster, A. C. Egberts , F. W. Gribnau , I. R. Edwards (1997) Causal or casual? The role of causality assessment in pharmacovigilance. Drug Safety. Dec ;17 (6): 374-89.

Räpple, T. (1998) Das Verbot bedenklicher Arzneimittel. Eine Kommentierung zu § 5 AMG. Nomos Verlagsgesellschaft. Baden-Baden. 
Reiss, J; P. Kitcher (2008) Neglected Diseases and Well Ordered Science. Contingency and Dissent in Science Project, CPNSS, London: London School of Economics

Santoro, M. (2005) Charting a Sustainable Path for the Twenty-First Century Pharmaceutical Industry. In M.A. Santoro, T.M. Gorrie. Ethics and the Pharmaceutical Industry. Cambridge: CUP.

Scheu, G. (2003) In Dubio Pro Securitate. Contergan, Hepatitis-/AIDS-Blutprodukte, Spongifprmer Humaner Wahn und kein Ende? Grundrechtliche Gefahrenvorsorge für Leib und Leben im Recht der Produkt- und Arzneimittelsicherheit - auch unter Aspekten der Europäisierung und Globalisierung. Nomos: Baden-Baden.

Schönhöfer P. (1993) Risikoabschätzungen bei Arzneimittelsicherheitsentscheidungen aus medizinischer Sicht. In: Damm/Hart, 1993: 95-107.

Searle J., D. Vanderveken (1985) Foundations of Illocutionary Logic, Cambridge University Press, 1985.

Slovic, P. (1987) Perception of risk. Science, 236: 280-285. Reprinted in: P. Slovic (ed.) (2000): 220230 .

Slovic, P. (2000) The perception of risk. London \& Sterling, VA: Earthscan.

Spielberg, S.P. (1993) Populations at Risk: Preditcting and Preventing Drug-induced Disease. Pharmacology and drug safety (2): 31-36.

Talbot, J.C.C., B.S. Nilsson (1998) Pharmacovigilance in the pharmaceutical industry. British Journal of Clinical Pharmacology (45): 427-431.

Temple, R., (2007) Quantitative decision Analysis: A Work in Progress. Clinical Pharmacology \& Therapeutics, vol. 82 (2): 127-130.

Waller, P.C., S.J.W. Evans (2003) A model for the future conduct of pharmacovigilance. Pharmacoepidemiology and drug safety, 12: 17-29.

Wolz B. (1988) Bedenkliche Arzneimittel als Rechtsbegriff. Frankfurt am Main. 